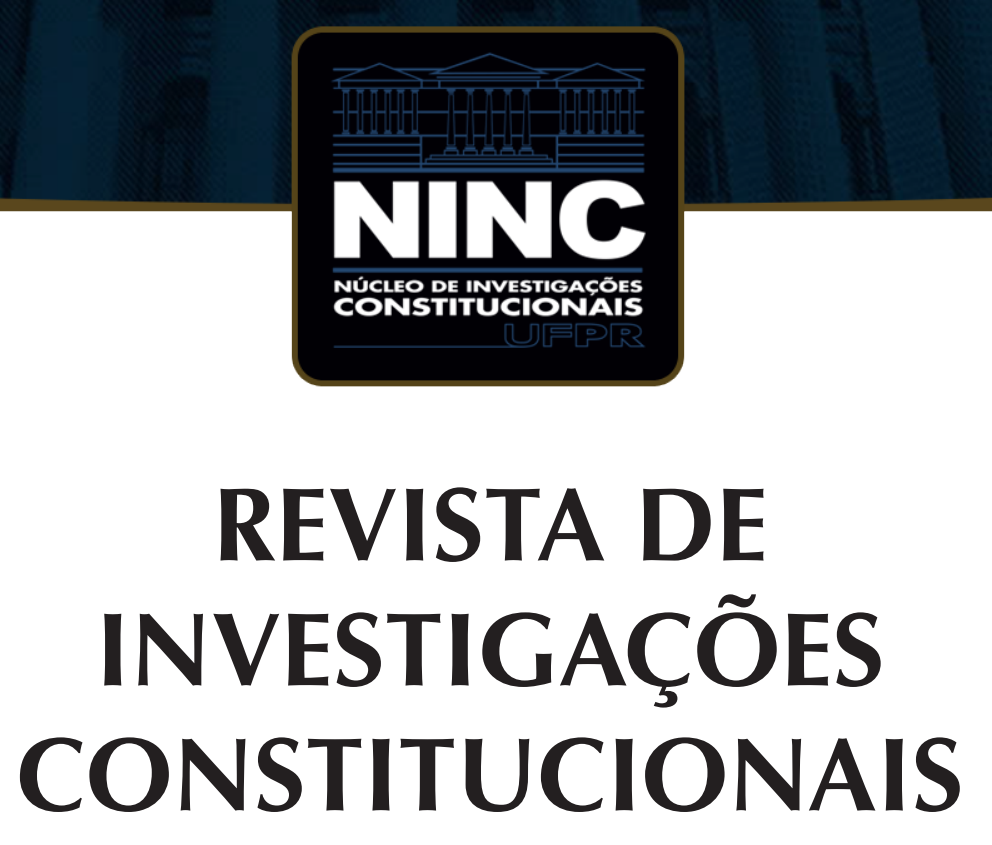

JOURNAL OF CONSTITUTIONAL RESEARCH

vol. 5 | n. 3 | setembro/dezembro 2018 | ISSN 2359-5639 | Periodicidade quadrimestral Curitiba | Núcleo de Investigações Constitucionais da UFPR | www.ninc.com.br 


\section{O mito de Marbury v. Madison: a questão da fundação da supremacia judicial}

\section{The myth of Marbury v. Madison: the question of the foundation of judicial supremacy}

\section{MICHELE CARVALHO SANTOS}

Faculdade de Direito do Sul de Minas (Brasil) crvmichele@gmail.com http://orcid.org/0000-0001-7322-0635

\section{LEANDRO CORRÊA DE OLIVEIRA**}

Faculdade de Direito do Sul de Minas (Brasil) leandro_coliveira@me.com http://orcid.org/0000-0001-7163-3364 Recebido/Received: 25.10.2017 / October 25 $5^{\text {th }}, 2017$ Aprovado/Approved: 30.08 .2018 / August $30^{\text {th }}, 2018$

\section{Resumo}

Marbury desempenha um importante papel no debate sobre a legitimidade do judicial review no sistema constitucional norte-americano. Diante disso, o artigo objetiva analisar teses críticas ao uso retórico do caso com o objetivo principal de desconstruir o mito de Marbury que garantiu que o tornasse a principal fonte de reivindicação da supremacia judicial. Para tanto, analisa contribuições revisionistas a fim de identificar a atual e real causa do louvor à decisão. Tem enquanto foco demonstrar como as citações de Marbury pela Suprema Corte não são apenas para justificar o judicial review em casos controversos, mas principalmente para afirmar a superioridade ou exclusividade judicial na interpretação constitucional. No

\section{Abstract}

Marbury plays an important role in the debate over the legitimacy of judicial review in the American constitutional system. Thus, this article aims to analyze critical theses to the rhetorical use of the case, with the main objective of deconstructing Marbury myth, which ensures that the case became the main source of the claim of judicial supremacy. Therefore, it analyzes revisionist contributions in order to identify the current and real cause of decision-making. Its focus is to show how Marbury's Supreme Court citation is not only to justify judicial review in controversial cases, but also primarily to assert judicial superiority or exclusivity in constitutional interpretation. In the end, the historical analysis of the political aspects of the case will allow a

Como citar esse artigo/How to cite this article: SANTOS, Michele Carvalho; OLIVEIRA, Leandro Corrêa de. O mito de Marbury v. Madison: a questão da fundação da supremacia judicial. Revista de Investigações Constitucionais, Curitiba, vol. 5, n. 3, p. 325-347, set./dez. 2018. DOI: 10.5380/rinc.v5i3.56030.

"Mestranda em Direito pela Faculdade de Direito do Sul de Minas (Pouso Alegre-MG, Brasil). Pós-graduada em Direito Material e Processual do Trabalho pela Pontifícia Universidade Católica de Minas Gerais. Integrante do Grupo de Pesquisa Jurisdição e Política. Advogada. E-mail: crvmichele@gmail.com.

** Professor do Mestrado em Direito da Faculdade de Direito do Sul de Minas (Pouso Alegre-MG, Brasil). Doutor em Direito pela Universidade Estácio de Sá. Mestre em Direito pela UFPR. Coordenador do Grupo de Pesquisa Jurisdição e Política. Advogado. E-mail: leandro_coliveira@me.com. 
final, a análise histórica dos aspectos políticos do caso permite uma leitura contextualizada, restando claro que a decisão de Marshall afastou-se da doutrina da supremacia judicial para adotar uma postura consistente com as premissas do constitucionalismo popular. contextualized reading, making clear that Marshall's decision moved away from the doctrine of judicial supremacy to embrace a consistent position with the premises of popular constitutionalism.

Palavras-chave: Marbury v. Madison; supremacia judicial; judicial review; constitucionalismo popular; departamentalismo.

Keywords: Marbury v. Madison; judicial supremacy; judicial review; popular constitucionalism; departmentalism.

\section{SUMÁRIO}

1. Introdução; 2. O revisionismo de Marbury; 3. As teses críticas de Larry Kramer e Keith Whittington ao uso retórico de Marbury para afirmar a supremacia judicial; 4. O contexto histórico-político da decisão e o contraste entre as concepções federalistas e republicanas sobre o papel da Corte; $\mathbf{5}$. Considerações finais; 6 . Referências.

\section{INTRODUÇÃO}

O célebre caso William Marbury v. James Madison ${ }^{1}$ de 1803 entrou para a história como o marco primeiro da incorporação definitiva do judicial review ao direito estadunidense. Reverenciado por grandes nomes do direito constitucional e na doutrina tradicional, o caso tornou-se objeto do revisionismo histórico e a sua invocação como precedente na contemporaneidade passou a ser alvo de críticas. Recentemente, afirma-se que tamanha ênfase resultou na criação de um mito.

Este trabalho não pretende rebaixar Marbury a um caso trivial. Como restará demonstrado, a circunstância politicamente delicada enfrentada por Marshall e sua solução estratégica ao declarar, pela primeira vez, de forma clara, a inconstitucionalidade de lei federal dos Estados Unidos - uma disposição do Judiciary Act de 1789 - adicionaram importância ao caso, singularizando a sua decisão.

A questão proposta neste trabalho pode fornecer uma outra perspectiva para o debate sobre o desenvolvimento da supremacia judicial; contra o uso retórico de Marbury na defesa deste arranjo institucional específico, que confia aos juízes a autoridade final de decidir sobre a inconstitucionalidade das leis. Pretende-se discutir e analisar como o precedente é associado com a atual prática do judicial review.

Essa análise é importante porque uma das questões mais salientes na atualidade busca um lugar; uma justificativa plausível para afirmação do judiciário como detentor da última palavra na interpretação da constituição. Assim, o debate sobre a origem dessa doutrina pode contribuir para refutar certas justificativas para sua adoção, como a afirmação convencional de que desde Marbury a Suprema Corte é a mais privilegiada intérprete da lei constitucional.

${ }^{1} 5$ U.S. (1 Cranch) 137 (1803). 
Sabendo que uma clara compreensão do judicial review contemporâneo requer a compreensão de suas raízes, no que segue, pretende-se analisar teses pioneiras e atuais do revisionismo de Marbury: as teses críticas traçadas por Larry Kramer e Keith Whittington ao seu uso retórico e, por fim, o contexto histórico-político da decisão, que evidencia o contraste entre a perspectiva de republicanos e federalistas sobre o papel da Corte.

\section{O REVISIONISMO DE MARBURY}

É um pensamento comum que o Chief Justice Marshall e a Suprema Corte dos Estados Unidos estabeleceram (ou criaram) o judicial review no caso de Marbury v. Madison em 1803. Descrita como "a mais importante decisão do direito constitucional americano" ${ }^{2}$, Marbury tornou-se objeto do revisionismo histórico legal. A recente doutrina revisionista sobre o caso tem desafiado esse entendimento em três aspectos, questionando o pioneirismo da decisão para o judicial review, a originalidade dos seus argumentos e a recepção e reconhecimento da decisão como significativa no seu próprio tempo.

Estes novos estudos não são apenas uma resposta à tradicional ênfase na importância de Marbury, isto é, à concepção tradicional que lhe confere o status de decisão histórica; são também uma resposta às frequentes invocações do caso pela Corte Rehnquist para apoiar o exercício controverso do judicial review. Tais trabalhos exploram as concepções americanas iniciais do instituto do controle de constitucionalidade e reexaminam o significado e o impacto de Marbury no estabelecimento desta doutrina.

Com efeito, diversos estudiosos têm observado que Marbury apenas se tornou parte do cânone constitucional após assumir uma forma mítica. Desmistificar o caso tornou-se necessário. Neste intento analisar-se-á as contribuições revisionistas, com foco nos aportes explicativos sobre o processo de ascendência constitucional do precedente e o surgimento de sua aura mítica.

Marbury foi uma decisão importante para seu tempo, sob as circunstâncias as quais foi proferida. Contudo, os elogios ao caso não são direcionados à decisão da Suprema Corte em exercer originariamente a jurisdição ou por discutir o uso adequado do mandado de segurança. Ao contrário, a doutrina tradicional foca na associação do caso ao princípio do judicial review. Desse modo, a grandeza de Marbury não é lembrada pelas qualidades intrínsecas da decisão nem pelo significado histórico quando foi proferido. Ao invés, "goza de grandeza porque a doutrina o associou intimamente com o judicial review".

${ }^{2}$ CHEMERINSKY, Erwin. Federal Jurisdiction. New York: Aspen Publishers, 2007. p. 12.

${ }^{3}$ DOUGLAS, Davison. The Rhetorical Use Of Marbury V. Madison: The Emergence Of a "Great Case", Wake Forest Law Review, vol. 38, p. 375-413, 2003. p. 378. 
Em primeiro lugar, Marbury não estabeleceu o judicial review, uma vez que a prática já tinha encontrado larga aceitação antes da histórica decisão, com um punhado de casos nos tribunais estaduais e federais e um pequeno número de casos na Suprema Corte. ${ }^{4}$ Larry Kramer registra que "comentadores geralmente parecem surpresos com o volume de evidências suportando judicial review antes de Marbury. Também ficam desconcertados pela aparente ausência de significativa controvérsia" sobre isso. ${ }^{5}$

A construção do raciocínio do Chief Justice Marshall não se deu ao acaso, apesar da ausência de norma constitucional expressa acerca do instituto do judicial review. Como registra William Treanor, cortes estaduais e federais já haviam começado a exercer o judicial review e fornecido justificativas para a possibilidade do controle antes de Marbury. ${ }^{6}$ Para ilustrar, em 1792, no caso Hayburn 7 , pela primeira vez, os juízes da Suprema Corte assumiam claramente que tinham o poder de invalidar um ato do Congresso. Em 1796, no caso Hylton v. United States ${ }^{8}$, a Suprema Corte contou, pela primeira vez, com o judicial review para decidir a constitucionalidade de um ato do Congresso. E, ainda três anos antes de Marbury, o Juiz Samuel Chase, resumia o estado de coisas, no caso Cooper v. Telfair: "isso é, de fato, uma opinião comum, que é expressamente admitido por todos os tribunais e alguns dos juízes têm, individualmente, no Circuits, decidido que a Suprema Corte pode declarar um ato do Congresso inconstitucional e, portanto, inválido". Mas, ele adicionou, "não há julgamento da Suprema Corte sobre o assunto".9

Apesar da notoriedade alcançada pelos argumentos de Marshall em Marbury, nada do que ele afirmou sobre o judicial review era novo. É bem verdade que Marbury foi o primeiro caso no qual a Suprema Corte inequivocamente declarou a inconstitucionalidade de um ato do Congresso, contudo, esta possibilidade já havia sido discutida, como no caso Hylton v. Unites States e na declaração do Juiz Chase em Cooper v. Telfair. Até a lógica da decisão de Marshall não foi original, teve como precursora aquilo que James Iredell ${ }^{10}$ e Alexander Hamilton ${ }^{11}$ haviam dito anos antes.

\footnotetext{
${ }^{4}$ Sobre este fato vide KRAMER, Larry D. The People Themselves: Popular Constitutionalism and Judicial Review, New York: Oxford University Press, 2004; Também vide: RAKOVE, Jack N. The Origins of Judicial Review: A Plea for New Contexts. Stanford Law Review, vol. 49, p. 1060-64, 1997.

${ }^{5}$ KRAMER, Larry. The People Themselves: Popular Constitutionalism and Judicial Review. New York: Oxford University Press, 2004. p. 98.

${ }^{6}$ TREANOR, William Michael. Judicial Review Before Marbury. Stanford Law Review, vol. 58, p. 455-462, 2005.

${ }^{7} 2$ U.S. (2 Dall.) 409 (1792).

${ }^{8} 3$ U.S. (3 Dall.) 171 (1796).

${ }^{9} \mathrm{O}$ termo "Circuits" utilizado por Samuel Chase refere-se aos circuitos regionais da justiça federal. (4 U.S. (4 Dall.) At 19. (1800))

${ }^{10}$ Vide: MCREE, Griffith John. Life and Correspondence of James Iredell: One of the Associate Justices of the Supreme Court of the United States, D. Appleton, 1857. Disponível em: https://books.google.com.br/books?i$\mathrm{d}=$ e1F7AAAAMAAJ. Acesso em 09 mai. 2017.

"Vide: The Federalist Papers, n. 78, 1788. Disponível em: <https://www.congress.gov/resources/display/content/The+Federalist+Papers >. Acesso em 09 mai. 2017.
} 
Marbury não teve um papel fundamental na criação da doutrina do judicial review. Aliás, a defesa da doutrina no caso é defeituosa ${ }^{12}$ É verdade que a linguagem eloquente e precisa empregada por Marshall começou a ser notada por alguns juízes em meados do século XIX, mas, no geral, quando juristas daquela época buscavam uma autoridade para explicar o poder do judicial review, geralmente, citavam o ensaio de Alexander Hamilton no Federalist Papers, os escritos de St. George Tucker de Blackstone ou a decisão de Justice Samuel Chase no caso Calder v. Bull13 ao invés da opinião de John Marshall. ${ }^{14}$

Para célebres juristas do século XIX, Marbury era lembrado como um caso que havia exposto a doutrina do judicial review de forma clara, sem contudo, nenhuma força criativa. ${ }^{15}$ Apenas, após um longo tempo, o caso passou a ser identificado como pedra de fundação do controle de constitucionalidade. Mas não evidenciou, como assinala Larry Kramer "um novo território para a teoria do judicial review".16 Michael Klarman, por sua vez, acusou a decisão de Marshall de fazer "nada para facilitar a aquisição pela Corte do ato político necessário para fazer o judicial review praticamente, como também, teoricamente significante". ${ }^{17}$

Em 1803, portanto, o poder do judicial review já estava suficientemente bem estabelecido. A novidade da decisão de Marshall estava em outro ponto: era o primeiro caso no qual a Suprema Corte declarava a inconstitucionalidade de um ato do Congresso. Esclarece Keith Whittington que, assim como foi percebido nos anos iniciais da República, o caso foi apenas um exemplo entre outros da afirmação do poder do judicial review. Mas não foi o caso que estabeleceu ou criou o instituto. Foi o caso onde a Suprema Corte "exerceu" ou "explicou" o judicial review. ${ }^{18}$

\footnotetext{
${ }^{12}$ A crítica clássica aos defeitos de Marbury na defesa do judicial review foi feita por BICKEL. Alexander. The Least Dangerous Branch: The Supreme Court At The Bar Of Politics. New Haven: Yale University Press, 1962. p, 1-14; vide também a crítica elaborada por ALSTYNE, William Van. A Critical Guide to Marbury v. Madison, Duke Law Journal, vol. 18, p. 1-47, 1969.

${ }^{13}$ Calder V. Bull, 3 U.S. 386 (1798).

${ }^{14}$ WHITTINGTON, Keith; RINDERLE, Amanda, Making. A Mountain Out Of A Molehill? Marbury And The Construction Of The Constitutional Canon. Hastings Constitutional Law Quarterly, Forthcoming, fev. 2012

${ }^{15}$ A obra Commentaries on American Law de James Kent, a qual celebra e enfatiza o judicial review, afirma que apenas em Marbury a questão sobre o judicial review havia recebido "clara e elaborada discussão". KENT. James. Commentaries on American Law. 1826; A obra de Hampton Carson por sua vez caracterizou todas as decisões anteriores a Marbury como "lentas, tímidas e à passos curtos". CARSON, Hampton L. The History Of The Supreme Court Of The United States, 1891. In: WHITTINGTON, Keith; RINDERLE, Amanda, Making A Mountain Out Of A Molehill? Marbury And The Construction Of The Constitutional Canon. Hastings Constitutional Law Quarterly, Forthcoming, fev. 2012.

${ }^{16}$ KRAMER, Larry. The People Themselves: Popular Constitutionalism and Judicial Review. New York: Oxford University Press, 2004. p. 115.

${ }^{17}$ KLARMAN, Michael. How Great were the 'Great' Marshall Court Decisions?, Virginia Law Review, vol. 87, p. 1111-1154, oct, 2001. p. 1126.

${ }^{18}$ WHITTINGTON, Keith; RINDERLE, Amanda. Making A Mountain Out Of A Molehill? Marbury And The Construction Of The Constitutional Canon. Hastings Constitutional Law Quarterly, Forthcoming, fev. 2012.
} 
No início do século XXI, Marbury tem um significado particular e ocupa um lugar especial e relevante do direito constitucional, mas nem sempre teve a importância que hoje lhe é dada. A doutrina revisionista observou que a importância e a identidade acerca da decisão mudaram ao longo do tempo. Aquilo que havia sido pouco notado e associado ao judicial review no século XIX, tornou-se, no século XX, um importante precedente para as cortes e para comentadores que buscavam justificar o mecanismo de controle jurisdicional.

Para analisar quando e como Marbury ganha importância, uma análise da quantidade e qualidade das citações do caso é necessária. Robert Clinton, talvez o primeiro a observar a que a Suprema Corte raramente notou o caso ou o associou ao judicial review durante o século XIX, sugere três padrões diferentes no nível de citação do judiciário quanto ao uso de Marbury pela Suprema Corte. O primeiro período de tempo abrange os primeiros cem anos depois que Marbury foi proferido. Durante este período, o caso foi pouco notado e raramente citado. Quando citado, não o era para apoiar a ideia do judicial review, mas para tratar de jurisdição e do uso do mandado de segurança. O segundo período se estende desde o centenário de aniversário de Marbury, em 1903, até Cooper v. Aaron, em 1958, quando apenas oito referências foram feitas ao caso em contraste com cinquenta casos nos quais a Corte citou Marbury para apoiar o judicial review durante o terceiro período. ${ }^{19}$

Em um recente artigo revisionista, Keith Whittington ${ }^{20}$ criou um original conjunto de dados para análise das citações do caso Marbury ao incluir os tribunais federais e estaduais, além da Suprema Corte, e ao examinar também referências ao caso em documentos do legislativo e executivo federais, bem como em livros e comentários jurídicos do século XIX. Este estudo fornece uma base mais abrangente do acolhimento e uso do mesmo, servindo de indicador para quando o caso se tornou historicamente importante. Os dados levantados neste trabalho contestam a afirmação de Robert Clinton, de que Marbury teria sido pouco notado em seu tempo. O caso era pouco notado se comparado aos níveis de citação que atingiu após o século XX. Segundo os dados, o padrão de citação mostra um aumento da taxa de citação de Marbury na Suprema Corte, nos tribunais federais, nos tribunais estaduais e nos debates políticos ao longo do tempo.

O comportamento de citação dos tribunais e da Corte, neste estudo, indica que Marbury tomou um novo significado no século XX. Se no século XIX era pouco lembrado como precedente de autoridade sobre o judicial review, logo que as controvérsias sobre o judicial review começaram a crescer durante a era Lochner, sua importância, de

\footnotetext{
${ }^{19}$ CLINTON, Robert Lowry. Marbury V. Madison and Judicial Review, Lawrence: University of Kansas Press, 1989.

${ }^{20}$ WHITTINGTON, Keith; RINDERLE, Amanda. Making A Mountain Out Of A Molehill? Marbury And The Construction Of The Constitutional Canon. Hastings Constitutional Law Quarterly, Forthcoming, fev. 2012.
} 
igual modo começou a crescer. E, se no período de menor controvérsia sobre o judicial review, ocorrida durante o New Deal, a importância de Marbury tendeu a diminuir, a reviravolta ocorreu após o caso Cooper. Após 1958, a taxa de citação do caso, inclusive especificamente como precedente para o poder do judicial review, obteve crescimento extraordinário, com a Suprema Corte liderando o caminho, acompanhada dos tribunais federais e estaduais.

As evidências sugerem que juízes passam a citar com maior frequência Marbury e focar na associação deste caso ao judicial review quando a legitimidade dos tribunais em exercer este poder passa a ser mais questionada. Whittington explicou esse fenômeno: "como o poder do judicial review se tornou mais saliente para o sistema constitucional e político e também mais contestado, juízes e comentadores 'se voltaram' para a poderosa retórica de John Marshall para ajudar a legitimar a instituição para as novas gerações". ${ }^{21}$

A narrativa federalista de um célebre Chief Justice, como John Marshall, começou a ser propagada nos anos iniciais da república. A ascendência de Marbury no direito constitucional americano, entretanto, se deu muito mais tarde, quase um século após ser proferido, somente quando seu significado foi reformulado de uma forma "mítica" e após ser colocado para o uso argumentativo. ${ }^{22}$

Juízes, entretanto, não foram os únicos a perceber e construir o significado de Marbury. Ao analisar uma variedade de obras de autores que primeiramente comentaram e discutiram sobre o caso, Whittington observou que o caso não era tratado com a reverência especial que lhe foi conferida posteriormente, com notáveis exceções. Para ele, "a visão heroica de John Marshall e a força de sua opinião em Marbury para a história constitucional americana foi propagada por famosos juristas, como James Kent, Joseph Story e George van Santvoord".23 Estes autores, entusiastas do judicial review e, pelo menos, quanto à James Kent e Joseph Story, amigos pessoais e aliados ideológicos do Chief Justice Marshall, começaram a exaltar o precedente, tornando-se, em parte, responsáveis pela aura mítica que envolve o caso nos dias de hoje.

O processo de canonização de Marbury se deu mais em razão da grande utilidade do precedente para a construção do poder das cortes em determinar o significado constitucional e exercer o judicial review do que pela importância do caso em seu próprio tempo. Whittington anota que, um caso, quando canonizado, torna-se

\footnotetext{
${ }^{21}$ WHITTINGTON, Keith; RINDERLE, Amanda. Making A Mountain Out Of A Molehill? Marbury And The Construction Of The Constitutional Canon. Hastings Constitutional Law Quarterly, Forthcoming, fev. 2012. p. 826.

${ }^{22}$ RUGER, Theodore. "A Question Which Convulses A Nation": The Early Republic's Greatest Debate About Judicial Review Power. Harvard Law Review, vol. 117, p. 826-890, 2004. p. 890.

${ }^{23}$ WHITTINGTON, Keith; RINDERLE, Amanda. Making A Mountain Out Of A Molehill? Marbury And The Construction Of The Constitutional Canon. Hastings Constitutional Law Quarterly, Forthcoming, fev. 2012. p. 859-860.
} 
importante não como um precedente, mas como um "símbolo" ou um "ícone judicial" com pouca relação com o caso original, mas com uma função simbólica para quem o usa. ${ }^{24}$

Conforme havia registrado Robert Clinton, a Suprema Corte, entre 1803 e 1887, não havia citado Marbury para o propósito de tratar sobre o judicial review, mesmo em casos altamente controversos como Dred Scott v. Sandford ${ }^{25}$ ou os Civil Rights Cases ${ }^{26}$, que invalidaram atos do Congresso. Por essa razão, o uso de Marbury pela Corte durante o século XIX sugere que a decisão era mais importante para as discussões pertinentes ao mandado de segurança, ao poder executivo ou à jurisdição original da Suprema Corte do que para discussão do judicial review. ${ }^{27}$

Ao final do século XIX, entretanto, quando o judicial review se tornou enraizado com questões altamente polêmicas ${ }^{28}$ e os tribunais passaram a ser instados pelos conservadores a exercer o judicial review de forma mais agressiva, Marbury passou a ser utilizado como instrumento para legitimar reivindicações por uma concepção expansiva de judicial review. A esse respeito, observa-se que:

Tanto para conservadores como para liberais, Marbury se tornou uma importante ferramenta retórica no debate em curso sobre o papel apropriado da Corte. Mas os juízes tem usado Marbury não apenas para defender o judicial review em casos controversos. Eles têm abraçado Marbury para outros propósitos instrumentais em particular, para fazer as interpretações constitucionais da Corte mais preeminentes do que aquelas de outros atores governamentais, um movimento que constitui a extensão do próprio Marbury. ${ }^{29}$

O uso de Marbury para conferir maior autoridade as interpretações constitucionais judiciais em relação as interpretações dos outros atores é uma visão expansiva do caso. Conforme explica Whittington, pelo menos duas leituras podem ser feitas do caso, a estreita interpreta a decisão como aquela julgou que tribunais federais podem declarar inconstitucionais os atos do Congresso. Para a ampla, "Marbury passou a representar

\footnotetext{
${ }^{24}$ Whittington busca descrever o processo de canonização de Marbury que teria possivelmente tornado o precedente substancialmente atraente para citações na prática judicial. WHITTINGTON, Keith; RINDERLE, Amanda. Making A Mountain Out Of A Molehill? Marbury And The Construction Of The Constitutional Canon. Hastings Constitutional Law Quarterly, Forthcoming, fev. 2012.

${ }^{25} 60$ U.S. (19 How.) 393 (1857)

${ }^{26} 109$ U.S. 3 (1883)

${ }^{27}$ CLINTON, Robert Lowry. Marbury V. Madison and Judicial Review, Lawrence: University of Kansas Press, 1989.

${ }^{28}$ Durante o final do século XIX e início do século XX, o judiciário envolveu-se na proteção dos direitos de propriedade e em frequente intervenção contra a legislação progressista promulgada sob a influência dos movimentos populistas e dos trabalhadores.

${ }^{29}$ DOUGLAS, Davison. The Rhetorical Use Of Marbury V. Madison: The Emergence Of a "Great Case", Wake Forest Law Review, vol. 38, p. 375-413, 2003. p. 378.
} 
uma proposição geral que cortes têm a última palavra na interpretação da Constituição e o poder de rever a validade dos atos dos outros ramos do governo". ${ }^{30}$

Barry Friedman afirma que tanto a interpretação restritiva quanto a ampliativa do caso criam mitos. Ele acredita que hoje há três tipos de mitos sobre Marbury. Denomina o primeiro de "Mito da Criação", uma visão maximalista de Marbury segundo a qual o judicial review nasceu por um ato do Justice John Marshall. O segundo mito, denominado de "Mito da História da Criação Desacreditada" conta uma história modesta de Marbury, nela o judicial review preexistia a Marshall, entretanto, o poder de estabelecer e manter o exercício deste instrumento sempre estivera com os juízes. E o último, o "Mito da Usurpação", tem uma visão minimalista de Marbury, segundo a qual o judiciário é o "ramo menos perigoso do governo" muito embora tenha, em algum momento, usurpado o poder da legislatura ou dos ramos políticos. ${ }^{31}$

Para Friedman estas visões são erradas porque nenhuma delas considera o importante papel do povo na manutenção do sistema do judicial review. Acredita ser improvável que juízes tenham estabelecido o judicial review sozinhos. Para ele, existe uma relação entre a opinião pública e a manutenção do judicial review frequentemente desconsiderada hoje. ${ }^{32}$

O foco histórico sobre o caso de Marbury na perspectiva do poder judicial também obscurece o entendimento acerca do papel do executivo e do legislativo. Cientistas políticos contemporâneos têm desafiado a afirmação comum que o judicial review é criado ou mantido em grande parte pelas decisões judiciais, adicionando uma voz a mais no coro do revisionismo de Marbury. O constitucionalista e cientista político Mark Graber ${ }^{33}$, por exemplo, criticou as obras constitucionais por promover uma visão juriscêntrica do judicial review.

Como visto, Marbury se tornou um ícone judicial no século XX; no entanto, o caso não tem sido apenas supervalorizado, mas também incompreendido. São frequentes as associações deste caso com a prática moderna do judicial review, bem como citações do mesmo para justificar o ativismo judicial. Conforme anotou Larry Kramer, o caso tornou-se "a pedra angular da jurisprudência" da Corte Rehnquist. ${ }^{34}$ Quanto a

\footnotetext{
${ }^{30}$ WHITTINGTON, Keith; RINDERLE, Amanda. Making A Mountain Out Of A Molehill? Marbury And The Construction Of The Constitutional Canon. Hastings Constitutional Law Quarterly, Forthcoming, fev. 2012. p. 829.

${ }^{31}$ FRIEDMAN, Barry. The Myths of Marbury. In: TUSHNET, Mark. (Ed.). Arguing Marbury v. Madison. California: Stanford University Press, 2005.

${ }^{32}$ FRIEDMAN. Barry. The Will Of The People: How Public Opinion Has Influenced The Supreme Court And Shaped The Meaning Of The Constitution. Farrar, Straus and Giroux: New York, 2009.

${ }^{33}$ Ao invés de enfatizar o poder judicial na criação no judicial review, Mark Graber descreve como oficiais eleitos e principalmente The Judiciary Act de 1789 fizeram mais em estabelecer o judicial review nos Estados Unidos do que a decisão de Marbury, vide: GRABER, Mark A. Establishing judicial review: Marbury and the Judicial Act of 1789. Tulsa Law Review, v. 38, n. 4, p. 609-650, 2003.

${ }^{34}$ KRAMER, Larry. Marbury And The Reatreat From Judicial Supremacy. Constitutional Commentary, Vol. 20, n. 2, p. 205-230, summer, 2003. p. 205.
} 
isso, revisionistas têm argumentado que a origem da moderna prática não pode ser atribuída a Corte de John Marshall. ${ }^{35}$ Isso porque a natureza do instituto tem mudado ao longo da história norte-americana, razão pela qual a prática moderna assumiu uma forma bem diferente daquela empregada por Marshall. ${ }^{36}$

Assim, o tipo de judicial review endossado em Marbury não guarda muita semelhança com a prática dos dias de hoje. Apesar de juristas, cientistas políticos e historiadores usarem o termo "judicial review" para descrever ambas as práticas, do século XVIII e do século XXI, o poder de judicial review que Marshall exerceu e que outros juízes exerceram em outros casos naquele tempo era mais modesto do que o exercido pela moderna Suprema Corte.

Segundo a breve análise das teses revisionistas empreendidas nas linhas antecedentes, pretendeu-se demonstrar que o caso não estabeleceu ou criou o judicial review, e que, há muito tempo, a invocação do caso pelos tribunais tem seguido padrões de conflitos judiciais e políticos com a intenção de justificar a prática controversa do judicial review. Ademais, atualmente, os tribunais têm se agarrado a Marbury para outros propósitos específicos, em especial, para afirmar a superioridade das interpretações constitucionais judiciais, provocando uma profunda perda no trato da intenção original.

\section{AS TESES CRÍTICAS DE LARRY KRAMER E KEITH WHITTINGTON AO USO RETÓRICO DE MARBURY PARA AFIRMAR A SUPREMA- CIA JUDICIAL}

A teoria constitucional tradicional tende a associar o ideal democrático com sua manifestação mais direita, a instituição do parlamento, enquanto a corte constitucional seria a representação do constitucionalismo. Nesse retrato, as controvérsias sobre quem deve ter a última palavra sobre a respeito do sentido da Constituição são classificadas a partir de duas inclinações contrapostas, a supremacia legislativa ou a supremacia judicial.

\footnotetext{
${ }^{35}$ Vide, por exemplo, a influente obra revisionista de: WOLFE, Christopher. The Rise Of Modern Judicial Review: From Constitutional Interpretation To Judge-Made Law. New York: Basic, 1986; Vide também a posição de: SNOWISS, Sylvia. Judicial Review and the Law of the Constitution. New Haven: Yale University Press. 1990. p. 109-175, 195. (Nesta obra revisionista da origem do judicial review, Snowiss argumenta que o judicial review moderno foi desenvolvido por Marshall, contudo, isso teria ocorrido não no caso Marbury, mas em outros casos sobre contratos e a clausula da supremacia. Salienta que tal construção teria adquirido a forma madura apenas algum tempo após o final da Corte Marshall.)

${ }^{36}$ Vide: WOLFE, Christopher. The Rise Of Modern Judicial Review: From Constitutional Interpretation To Judge-Made Law, 1986; GRIFFIN, Stephen. The Age of Marbury: Judicial Review in a Democracy of Rights. In: TUSHNET, Mark. (Ed.). Arguing Marbury v. Madison. California: Stanford University Press, 2005; SNOWISS, Sylvia. Judicial Review and the Law of the Constitution. New Haven: Yale University Press. 1990. p. 196. ("That Marbury cannot support authoritative judicial exposition of the Constitution is not surprising").
} 
Ressurge, contemporaneamente, na literatura da teoria constitucional um terceiro tipo de resposta que desafia a supremacia judicial, sem, contudo, rejeitar o judicial review. Trata-se do princípio do constitucionalismo popular, o qual tem disputado espaço, praticamente desde o começo, na teoria constitucional norte-americana, com o constitucionalismo legal.

Uma das visões mais influentes do constitucionalismo popular foi apresentada por Larry Kramer, cujos trabalhos defendem o sistema no qual "o papel do povo não se limita a atos ocasionais de construções constitucionais, mas inclui controle ativo e contínuo sobre a interpretação e aplicação da lei constitucional" ${ }^{37}$ em oposição ao sistema largamente aceito hoje, que realoca esta autoridade interpretativa no judiciário.

Outro autor que tem se empenhado na defesa da interpretação extrajudicial da Constituição, argumentando alguma variação do constitucionalismo popular é Keith Whittington. Em suas obras Constitutional Interpretation e Constitucional Construction, o autor, respectivamente, defende o originalismo e descreve como atores políticos ajudam a formular o significado constitucional. Whittington reivindica a soberania popular sustentando a intenção original dos framers da Constituição na adoção do departamentalismo.

O departamentalismo ou construção coordenada é um sistema no qual cada um dos três departamentos do governo possuem independentes e coordenadas autoridades para interpretar a constituição. Cada departamento possui um poder delegado pelo povo. Este sistema pode ser reconhecido como um autêntica expressão do constitucionalismo popular por preservar a essência deste princípio em uma forma mais complexa. ${ }^{38}$

Ambos autores argumentam a adoção de uma alternativa para a supremacia judicial. Preconizam um arranjo institucional que confira maior ênfase à perspectiva coletiva de autogoverno democrático de sorte que a capacidade e responsabilidade políticas do povo não acabe enfraquecida.

Larry Kramer, em seu trabalho revisionista da origem histórica do judicial review, The People Themselves, contribuiu para desmistificação de que Marbury seria a origem do que ele chamou de primeira concepção do judicial review e oferece uma leitura de como os argumentos empregados no caso teriam seguido as premissas do constitucionalismo popular.

\footnotetext{
${ }^{37}$ KRAMER, Larry. Popular Constitutionalism, Circa 2004. California Law Review, vol. 92, n. 4, p. 959-1011, jul. 2004. p. 959.

${ }^{38}$ Essa perspectiva é oferecida por Larry Kramer que elabora fusão entre o constitucionalismo popular e o departamentalismo. Este autor refere-se a teoria departamentalista como maior expressão institucional do constitucionalismo popular, vide: KRAMER, Larry. The People Themselves: Popular Constitutionalism and Judicial Review, New York: Oxford University Press, 2004. p.106-201.
} 
Neste trabalho, Larry Kramer observou que há "excessiva celebração de Marbury v. Madison, cuja grande significância parece imune a correção histórica". ${ }^{39}$ Ele descreve como o caso tem tido grande destaque nas narrativas que retratam a Corte sublimemente em uma tendência de confundir a história constitucional com a história da doutrina da Suprema Corte. Nestas histórias, as resistências as visões constitucionais da Corte são ignoradas, quando não demonizadas, e os momentos do constitucionalismo popular, minimizados. Para ele, o maior objetivo disso seria fazer parecer que sempre houve larga aceitação da supremacia judicial.

Mais recentemente, Keith Whittington se juntou a crítica elaborada por Larry Kramer com a seguinte assertiva: "o mito de Marbury afirma que a supremacia judicial sempre esteve conosco desde o início".40 Para Whittington, a supremacia judicial na história dos Estados Unidos tem fundações políticas e o intuito da criação do mito de Marbury é esconder este fato; é evitar as questões sobre a origem da afirmação que a Corte tem o papel na definição dos sentidos constitucionais. A esse respeito, ele ridiculariza a autoconfiança da Corte Rehnquist em citar algumas sentenças de Marbury neste intento, afirmando que isto é puramente um "pensamento ilusório por parte dos juízes".41

A Suprema Corte, entretanto, não é a única expositora desta visão. Whittington acredita que mito de Marbury permanece forte principalmente porque progressistas e conservadores celebram o caso para propor uma visão de autoridade judicial errada, apesar deste golpe judicial já ter sido denunciado há tempos. ${ }^{42}$

Este autor também tem criticado os argumentos de acadêmicos defensores da Corte que assumem que a supremacia judicial é essencial ao constitucionalismo americano, sem contudo, enfrentar as questões sobre as fundações desta doutrina. A esse respeito, Whittington apontou Ronald Dworkin como exemplo de acadêmico que só teria aumentado os mistérios sobre esta questão ao afirmar que a "autoridade interpretativa já havia sido distribuída pela história, e detalhes da responsabilidade institucional dependem de

\footnotetext{
${ }^{39}$ KRAMER, Larry. The People Themselves: Popular Constitutionalism and Judicial Review, New York: Oxford University Press, 2004. p. 229-230; Vide também comentários de Kramer à obra do historiador legal William Nelson (Marbury v. Madison: The origens and Legacy of Judicial Review) criticando à incapacidade de historiadores legais de aceitar a desconstrução final e completa do mito de Marbury, pois não se cansam de buscar outras razōes para celebrar o caso, em: KRAMER, Larry. The Pace and Cause of Change. Marshall Law Review, vol. 37, n. 2, p. 357-389, winter, 2004.

${ }^{40}$ WHITTINGTON, Keith. Political Foundations of Judicial Supremacy. Princeton: Princeton University Press, 2007. p. 9.

${ }^{41}$ WHITTINGTON, Keith. Political Foundations of Judicial Supremacy. Princeton: Princeton University Press, 2007. p. 4-9 e 280. (O autor registra que a Corte Rehnquist utilizou a máxima de John Marshall, é dever do judiciário "dizer o que a lei é", em trinta e sete casos entre 1986 e 2004)

${ }^{42}$ WHITTINGTON, Keith. Political Foundations of Judicial Supremacy. Princeton: Princeton University Press, 2007. p. 285.
} 
interpretação e não de criação a partir do nada".43/44 Por outro lado, não somente fãs do judiciário fazem este tipo de argumento ou revelam desconhecer as origens da supremacia judicial. Kramer criticou muitos acadêmicos, inclusive revisionistas como Silvia Snowiss e Robert L. Clinton, de contribuir para "uma nova mitologia em que a supremacia é tratada como o ponto de vista lógico e inexorável de um progresso benéfico".45

O argumento de que a supremacia judicial é um desenvolvimento muito recente na história constitucional não é novo, mas até então as fundações dessa doutrina permaneciam pouco exploradas. Larry Kramer suspeita que talvez a maioria das pessoas que apoiam a supremacia judicial hoje não pensam muito sobre isso, ou acreditam que "isto decorre naturalmente do status de lei da Constituição ou que a supremacia foi originariamente intencionada ou estabelecida desde o começo" ${ }^{\prime 46}$, assunções que, para ele, são evidentemente erradas.

Em que pese esse pensamento comum, Kramer e Whittington alertam que os argumentos de Marshall não podem ser usados para afirmação da supremacia judicial porque a prática do judicial review naquele tempo era mais modesta do que a exercida nos dias atuais pela Suprema Corte. Whittington descreveu os argumentos de Marshall como "temperados". Segundo ele, Marshall havia temperado sua forte afirmação da autoridade judicial sobre a interpretação constitucional, porque no contexto temporal no qual Marbury foi proferido, "estava claro que outras instituições políticas tinham ativa atuação na interpretação da Constituição e tais interpretações eram largamente aceitas como obrigatórias".47

Para este autor, apenas em meados do século XX os juízes da Suprema Corte teriam abandonado a modéstia de suas afirmações. Isto ocorreu mais especificamente em 1958, quando o Chief Justice Earl Warren interpretou à sua maneira a famosa sentença de John Marshall a qual declara ser dever judicial "dizer o que é a lei" para afirmar que o judiciário federal é supremo expositor da lei constitucional. Foi no caso Cooper v. Aaron, portanto, que o Chief Justice Earl Warren "transformou Marbury em um símbolo moderno de poder judicial", ao remodelar os argumentos de Marshall tornando-os um "standard judicial e retórico legal".48

${ }^{43}$ DWORKIN, Ronald. Freedom's Law: The Moral Reading of the American Constitution, Harvard University Press, 1996. p. 34-35.

${ }^{44}$ WHITTINGTON, Keith. Political Foundations of Judicial Supremacy. Princeton: Princeton University Press, 2007. p. 9.

${ }^{45}$ KRAMER, Larry. Marbury And The Reatreat From Judicial Supremacy, Constitutional Commentary, Vol. 20, n. 2, p. 205-230, summer, 2003. p. 205-206.

${ }^{46}$ KRAMER, Larry. The People Themselves: Popular Constitutionalism and Judicial Review, New York: Oxford University Press, 2004. p. 234.

${ }^{47}$ WHITTINGTON, Keith. Political Foundations of Judicial Supremacy. Princeton: Princeton University Press, 2007. p. 2-9.

${ }^{48}$ WHITTINGTON, Keith; RINDERLE, Amanda. Making A Mountain Out Of A Molehill? Marbury And The Construction Of The Constitutional Canon. Hastings Constitutional Law Quarterly, Forthcoming, fev. 2012. p. 825. 
Igualmente contra a tradição da supremacia judicial inventada por John Marshall, Larry Kramer afirmou que a decisão em Marbury é totalmente consistente com as premissas do constitucionalismo popular. ${ }^{49}$ Este autor fez contundente crítica à interpretação das palavras de Marshall na decisão feita pela Corte Warren na decisão Cooper v. Aaron. Segundo ele, os juízes em Cooper não estavam tentando reproduzir os argumentos de Marshall, ao invés, estavam tentando produzir novos argumentos. Para ele, a Corte "induziu forçosamente a reafirmação de sua supremacia" insistindo que Marbury disse algo que, na verdade, não disse..$^{50}$

A famosa expressão da decisão "enfaticamente, é a província e o dever do Poder Judiciário dizer o que é a lei", conforme esclarece Larry Kramer, quando lida isoladamente, "com nossos olhos modernos", e fora do contexto histórico em que foi escrito, pode ser entendida como um dever unicamente da corte de dizer o que a constituição significa, entretanto, a partir de análise histórica da formação constitucional norte-americana, é possível entender que Marshall, na verdade, buscava, tão somente, reafirmar o poder do Judiciário no processo de interpretação constitucional. ${ }^{51}$

Kramer apoia a leitura revisionista de Marbury ao afirmar que o caso, quando lido em contexto, é melhor compreendido como "fuga" ou "recuo" da doutrina da supremacia judicial. Para ele, as palavras usadas por Marshall, na decisão, com intuito de justificar o judicial review de forma nenhuma pode ser lida para endossar tal ideia. Isso porque Marshall reiterou e insistiu que o judiciário não era menos encarregado pelo cumprimento da Constituição do que os demais ramos, a exemplo da famosa afirmação: "cortes, assim, como os outros departamentos, são limitados por este instrumento" ${ }^{\prime 2}$, de modo que teria explicitamente abraçado a teoria do judicial review limitado, agrupada na abordagem departamental da separação de poderes defendida por Madison e Thomas Jefferson..$^{53}$

Nessa concepção republicana moderada, a interpretação constitucional é uma responsabilidade compartilhada entre os iguais e coordenados departamentos do governo. Assim, o entendimento do judicial review na posição de John Marshall no caso Marbury está longe de ser um clamor por uma superioridade ou exclusividade judicial no poder de interpretar.

\footnotetext{
${ }^{49}$ KRAMER, Larry. The People Themselves: Popular Constitutionalism and Judicial Review. New York: Oxford University Press, 2004. p. 125.

${ }^{50}$ KRAMER, Larry. The People Themselves: Popular Constitutionalism and Judicial Review. New York: Oxford University Press, 2004. p. 221

${ }^{51}$ KRAMER, Larry. The People Themselves: Popular Constitutionalism and Judicial Review. New York: Oxford University Press, 2004. p. 125-126; KRAMER, Larry. Marbury And The Reatreat From Judicial Supremacy. Constitutional Commentary, Vol. 20, n. 2, p. 205-230, summer, 2003. p. 214.

${ }^{52} 5$ U.S. (1 Cranch) 137 (1803) p. 180.

${ }^{53}$ Registra ainda que, apesar de John Marshall não ter adotado os argumentos federalistas na decisão de Marbury, sua crença pessoal na supremacia da Suprema Corte parece clara em M'Culloch v. Maryland, 17 U.S. (4 Wheat.) p. 316, 401. (KRAMER, Larry. Marbury And The Reatreat From Judicial Supremacy. Constitutional Commentary, Vol. 20, n. 2, p. 205-230, summer, 2003. p. 214, 228.)
} 
A supremacia judicial é encarada por Larry Kramer como o principal inimigo do constitucionalismo popular. ${ }^{54}$ Isso porque, no mundo do constitucionalismo popular é impensável que a Constituição seja entregue nas mãos dos juízes e que o povo fique com pouca autoridade interpretativa. Este sistema não nega aos juízes o poder do judicial review, mas nega que o Judiciário seja o supremo expositor do sentido constitucional.

A nova jurisprudência da Corte é clara em identificar a autoridade judicial como a última interprete da Constituição. Tal qual a Corte Warren, a Corte Rehnquist empregou citações de Marbury para este efeito. O caso City of Boerne v. Flores ${ }^{55}$ é paradigmático nesse sentido. No mesmo propósito, três anos depois, o Chief Justice Rehnquist escreveu em United States v. Morrison: "Não há dúvidas que os ramos políticos tem um papel na interpretação e aplicação da Constituição, mas desde Marbury esta Corte tem permanecido a última expositora da texto constitucional".56

Como se observa, a Suprema Corte não tem feito muito mais para justificar sua afirmação como árbitro final do sentido constitucional do que apontar os argumentos de Marshall e citar a famosa frase "é a província e o dever do judiciário dizer o que é a lei". Este fato demonstra que a Corte já não se preocupa em se justificar por uma teoria do judicial review e sugere que a supremacia judicial segue sem grandes desafios.

Em um artigo publicado na Harvard Law Review, em 2001, Larry Kramer ofereceu poderosa crítica os fundamentos originalistas da Corte Rehnquist e ao modo como ela citou Marbury para propor que a leitura judicial da Constituição é'a correta'. Pretende desnaturalizar um conjunto de suposições da Corte porque os juízes:

(...) eles estão enganados. Quanto a isso, não segue automaticamente que eles estão errados em ampliar o alcance de sua autoridade. Mas, é certo que eles precisam de uma explicação e uma justificativa que eles ainda não forneceram. Certamente, é preciso fazer mais do que citar Marbury fora do contexto ou oferecer interpretações realmente ruins da Fundação".57

\footnotetext{
${ }^{54} \mathrm{Nas}$ palavras do autor, "Judicial supremacy is an intellectual construct whose whole function and effect is to forestall popular constitutionalism and to extend how far courts can go before triggering a popular reaction. As such, it pervades the whole edifice of constitutional law, giving the justices freedom not just at the outer edges but also in areas that are not hugely controversial." (KRAMER, Larry. Generating Constitutional Meaning. California Law Review, vol. 94, n. 5, p. 1439-1453, 2006. p. 1452.).

${ }^{55}$ A decisão City of Boerne empregou uma citação de Marbury argumentando que "If Congress could define its own powers by altering the Fourteenth Amendment's meaning, no longer would the Constitution be "superior paramount law, unchangeable by ordinary means." It would be "on a level with ordinary legislative acts, and, like other acts, ... alterable when the legislature shall please to alter it." Marbury v. Madison, 1 Cranch, at 177." (City of Boerne v. Flores. 521, U.S. (1997)).

${ }^{56}$ United States v. Morrison, 529 U.S. 598 (2000).

${ }^{57}$ KRAMER, Larry. The Supreme Court 2000 Term: Foreword: We the Court. Harvard Law Review, vol. 115, p. 4-169, jan., 2001. p. 162-163.
} 
Pela inexistência de justificativa plausível apresentada pela Corte, Whittington percebeu que hoje a evidência para atribuir a autoridade interpretativa aos tribunais é simples, é Marbury. A Suprema Corte tem sido a grande expositora desta afirmação, mas não está sozinha. Defensores da supremacia judicial geralmente recorrem a Marbury para fazer acreditar que a supremacia judicial sempre esteve entre nós. Whittington e Kramer não caem, no entanto, na defesa convencional de uma superioridade ou exclusividade judicial na interpretação constitucional. Para eles, existe robusta tradição de autoridade interpretativa constitucional fora das cortes que afronta a narrativa da supremacia judicial.

Estes autores pretendem assim demonstrar que a supremacia judicial não emergiu como uma teoria constitucional dominante nos anos iniciais da história norte-americana, da forma como os juristas que enfatizam o precedente de Marbury sugerem. Foi ao longo do tempo que o judiciário veio ganhando mais autoridade sobre a interpretação constitucional. Conforme Larry Kramer explica, o sistema do constitucionalismo popular precedeu a doutrina da supremacia judicial e foi o princípio dominante na maior parte da história norte-americana. Neste sistema, o judiciário, assim como o legislativo, não possuía a autoridade interpretativa final, a qual residia no "the people themselves".58

O curso da história norte-americana é marcado por luta entre vários atores políticos pela autoridade de interpretar a Constituição. Uma luta com variadas intensidades e também com momentos de maior deferência de um dos ramos perante outro. Atualmente, há maior deferência dos ramos executivo e legislativo ao judiciário. Neste ponto, esclarece Whittington que os demais ramos encontraram na supremacia judicial certos benefícios políticos. ${ }^{59}$ Somando a isso, há uma passividade atual do povo relativamente a autoridade da Corte. ${ }^{60}$

A autoridade judicial de interpretar a Constituição, portanto, não é absoluta. Estes autores argumentam que a Constituição norte-americana não fez a opção por este tipo de arranjo institucional específico. A autoridade constitucional é dinâmica e não pode ter sido distribuída uma vez por todas. O poder para distribui-la não está na tradição, nem na história. Em uma palavra: o poder de decidir reside no povo.

\footnotetext{
${ }^{58}$ KRAMER, Larry. Popular Constitutionalism, Circa 2004. California Law Review, vol. 92, n. 4, p. 959-1011, jul. 2004.

${ }^{59}$ WHITTINGTON, Keith. Political Foundations of Judicial Supremacy. Princeton: Princeton University Press, 2007. p. 15-27.

${ }^{60}$ Segundo Kramer, deve ser reconhecida como uma questão aberta pelo povo americano se o constitucionalismo popular deve prevalecer, pois o povo ainda pode insistir no seu direito de controlar a Constituição. Nas suas palavras: "Judicial supremacy is not the logical or inevitable product of experience and progress. It remains now, as it was in the beginning, but one side in a recurrent and ongoing struggle to determine the proper role of ordinary citizens in a republic." (KRAMER, Larry. Marbury And The Reatreat From Judicial Supremacy. Constitutional Commentary, Vol. 20, n. 2, p. 205-230, summer, 2003. p. 230.) Vide também: KRAMER, Larry. The People Themselves: Popular Constitutionalism and Judicial Review, New York: Oxford University Press, 2004. p. 227-248.
} 
A questão proposta por estes autores é: quem deve ter a autoridade de estabelecer os casos difíceis? Ou ainda, a Corte deve ser a suprema expositora do significado constitucional? Isto é desafiar a supremacia judicial. Trata-se de buscar as justificativas por que as interpretações constitucionais feitas pelo judiciário devem ter forte deferência pelos outros atores constitucionais. Responder a estas questões, por sua vez, requer mais do oferecer uma interpretação descontextualizada de Marbury. Quanto a isso, basta ler o caso em seu contexto para que as percepções iniciais sobre uma afirmação da supremacia judicial por Marshall desapareçam.

\section{O CONTEXTO HISTÓRICO-POLÍTICO DA DECISÃO E O CONTRAS- TE ENTRE AS CONCEPÇÕES FEDERALISTAS E REPUBLICANAS SOBRE O PAPEL DA CORTE}

A conjuntura política à época da decisão, em 1803, era marcada por um embate político entre federalistas e republicanos. O partido republicano disputou as eleições presidenciais no final do ano de 1800, ganhando pelo voto popular. Derrotados nas urnas, os federalistas tomaram uma série de ações em um esforço para preservar vestígios da influência do partido durante a próxima administração, como a adoção do Circuit Courts Act. Este ato reduzia o número de juízes da Suprema Corte de seis para cinco, aliviava a Corte de serviço enquanto estabelecia seis novos tribunais no circuito, com dezesseis juízes ao todo, que foram rapidamente nomeados pelo presidente John Adams e aprovados pelo Senado.

Imediatamente após Thomas Jefferson assumir o cargo da presidência ordenou ao Secretário de Estado James Madison que mantivesse em suspenso as posses dos juízes que ainda não tinham sido entregues. Uma dessas era devida à William Marbury. Em 1801, Marbury impetrou um writ of mandamus na Suprema Corte para obrigar Madison a realizar sua posse. Uma série de questões importantes e políticas surgiram, mas a questão do judicial review surgiu apenas após um ano, em 1802, enquanto o caso de Marbury ainda estava pendente e quando o Congresso Republicano debatia sua autoridade para revogar o Circuit Courts Act.

Com a revogação do Circuit Courts Act pelo Congresso, os partidos reagiram. Para os federalistas, o Repeal Act representou muito mais um grave ataque a independência do judiciário do que uma falha da administração em realizar algumas posses, como na circunstância do caso de Marbury. ${ }^{61}$ Eles argumentavam a inconstitucionalidade do ato de revogação e condenavam seus efeitos fatais contra a Constituição, ${ }^{62}$ enquanto republicanos pensavam que esta era a vitória do Republicanismo.

${ }^{61}$ FRIEDMAN. Barry. The Will Of The People: How Public Opinion Has Influenced The Supreme Court And Shaped The Meaning Of The Constitution. New York: Farrar, Straus and Giroux, 2009. p. 52-55.

${ }^{62}$ Os Federalistas sustentavam a inconstitucionalidade do Repeal Act. Para Friedman: "The Federalists staked their case on the Constitution. Article III of the Constitution states that judges are to "hold their Offices during 
Apesar do clamor dos federalistas pela inconstitucionalidade do ato de revogação do Congresso que anulou a posse de juízes, a Suprema Corte não pode fazer mais do que se submeter ao ato. Evidentemente, desafiar diretamente os republicanos poderia apenas prejudicar a Corte. Então, ao fazer uso de uma tática para evitar conflito direito com a posição de Jefferson ${ }^{63}$, a Corte decidiu que Ihe faltava jurisdição para julgar o caso e declarou inconstitucional a seção 13 do Judiciary Act de 1789 por ter concedido jurisdição original não autorizada pela Constituição.

Possivelmente a posição extremamente precária da Corte teria conduzido Marshall a fazer uso do judicial review. ${ }^{64}$ Como salienta Christopher Wolfe, a decisão deve ser interpretada como um ato de timidez do judiciário federalista frente ao partido republicano dominante nos departamentos legislativo e executivo, visto que qualquer afronta à presidência poderia prejudicar a posição pública do departamento judicial, que ainda não havia estabelecido completamente seu poder aos olhos da nação. ${ }^{65}$

A esse respeito, observa-se que a Suprema Corte, naquele contexto, não contava com um amplo apoio difuso e, certamente, não era um departamento forte, capaz de desafiar o executivo e o legislativo em um só ato. Há apenas alguns anos, Alexander Hamilton havia se expressado que não haveria porque se preocupar com um departamento tão fraco, referindo-se ao judiciário, como "o departamento menos perigoso" dos três departamentos do governo. ${ }^{66}$ Ademais, e como já esperado, as decisões da Corte durante este período não tinham o cunho de desafiar outros ramos, ao invés, eram muito bem planejadas para alinhar a Corte à visão dos demais atores nacionais. ${ }^{67}$

good Behavior" and may be removed only by impeachment. Because the new circuit court positions the Republicans sought to abolish had already been filled Federalists argued, the move to repeal the Circuit Judges Act represented an unconstitutional removal of the judges". (FRIEDMAN. Barry. The Will Of The People: How Public Opinion Has Influenced The Supreme Court And Shaped The Meaning Of The Constitution. New York: Farrar, Straus and Giroux, 2009. p. 53.).

${ }^{63}$ Existe certo consenso na doutrina que Marshall utilizou uma tática brilhante na decisão, entretanto, autores divergem se isso foi uma jogada claramente política ou a mais neutra possível, vide, por exemplo: "It was a risky strategy. Marshall's lecture infuriated Jefferson, who perceived it as a politically motivated attack on his presidency". (KRAMER, Larry. The People Themselves: Popular Constitutionalism and Judicial Review, New York: Oxford University Press, 2004. p. 123); "His aim was to isolate the judiciary from partisan politics as much as possible". (WOOD, Gordon. The Origins Of Judicial Review Revisited, Or How The Marshall Court Made More Out Of Less. Washington \& Lee Law Review, vol. 56, n. 3, p. 787-803, 1999. p. 806); "While it is commonplace for historians and legal commentators to assert that Marshall's interpretation of the statute was motivated by crass political aims... what were those "political" purposes: were they partisan or "constitutional"?" (WOLFE, Christopher. The Rise Of Modern Judicial Review: From Constitutional Interpretation To Judge-Made Law, New York: Basic, 1986. p. 86-87.).

${ }^{64}$ Segundo Larry Kramer o mesmo resultado poderia ter sido obtido facilmente em outras circunstâncias sem a necessidade da anulação de uma lei, vide: KRAMER, Larry. The People Themselves: Popular Constitutionalism and Judicial Review, New York: Oxford University Press, 2004. p. 123-124.

${ }^{65}$ WOLFE, Christopher. The Rise Of Modern Judicial Review: From Constitutional Interpretation To JudgeMade Law, New York: Basic, 1986. p. 87.

${ }^{66}$ The Federalist Papers, n. 78, 1788. Disponível em: <https://www.congress.gov/resources/display/content/ The+Federalist+Papers>

${ }^{67}$ WHITTINGTON, Keith. Political Foundations of Judicial Supremacy. Princeton: Princeton University Press, 2007. p. 111. 
Os federalistas na época haviam começado a expor uma teoria mais ampla de judicial review e mais ambiciosa - teoria hoje reconhecida como supremacia judicial. Entretanto, diante da clara impotência da Corte naquele período dificilmente Marshall teria adotado os argumentos federalistas em Marbury, contrariando a maioria republicana. Marshall, teria temperado seus argumentos na decisão ao afirmar que "é evidente que os framers da constituição contemplaram o instrumento como uma regra para os tribunais, assim como para a legislatura".68

Assim, embora Marshall fosse um federalista, ele evitou os argumentos federalistas na decisão, pois "as circunstâncias de Marbury conduziram Marshall a escrever cautelosamente e a formular a autoridade da Corte em nulificar a legislação de forma conservadora".69 Nesse mesmo sentido, o eminente historiador Gordon Wood afirma que a decisão de Marshall "não iniciava uma cruzada pela supremacia judicial”, ao invés, era tão sutil que parecia que os Republicanos haviam gostado mais dela do que os Federalistas. $^{70}$

A decisão de Marshall não discordou explicitamente da posição de Jefferson, apesar de não julgar o caso a favor dos Republicanos. Na verdade, Larry Kramer e Keith Whittington argumentam que a decisão de Marshall se aproxima mais da teoria departamentalista defendida por Jefferson do que uma defesa da supremacia judicial conforme advogado pelos federalistas.

Por certo Thomas Jefferson foi um presidente comprometido com a teoria departamentalista, explicou e defendeu seu bom cumprimento. Ele negou que qualquer ramo do governo federal pudesse ser exclusivo ou final quanto aos poderes delegados pela Constituição. Sobre seu entendimento sobre a interpretação constitucional, argumentou que os departamentos do governo deveriam ser "coordenados e independentes", pois "cada ramo tem igual direito de decidir por si mesmo o sentido da Constituição".71

Para os republicanos, a teoria departamentalista significava que "a autoridade das constituições estão acima dos governos, e a soberania do povo acima das constituições".72 De modo geral, este partido não rejeitava o judicial review. Na verdade, aceitava a possibilidade de cada departamento do governo expressar sua visão. Por outro lado, nenhum dos departamentos poderia ter a palavra final, pois as controvérsias

\footnotetext{
${ }^{68} 5$ U.S. (1 Cranch) 137 (1803).

${ }^{69}$ KRAMER, Larry. The People Themselves: Popular Constitutionalism and Judicial Review, New York: Oxford University Press, 2004. p. 125.

${ }^{70}$ WOOD, Gordon. The Origins Of Judicial Review Revisited, Or How The Marshall Court Made More Out Of Less. Washington \& Lee Law Review, vol. 56, n. 3, p. 787-803, 1999. p. 806.

71 JEFFERSON, Thomas. The Writtings of Thomas Jefferson. In: WHITTINGTON, Keith. Political Foundations of Judicial Supremacy. Princeton: Princeton University Press, 2007. p. 32-33.

${ }^{72}$ KRAMER, Larry. The People Themselves: Popular Constitutionalism and Judicial Review, New York: Oxford University Press, 2004. p. 137.
} 
constitucionais deveriam ser resolvidas em última instância pelo povo. Em síntese, os republicanos rejeitavam a supremacia judicial.

Federalistas evidentemente discordavam. Compostos predominantemente pela elite norte-americana, mantinham certo temor em relação ao populismo e a demagogia, ao tempo em que defendiam a ideia de passiva deferência dos cidadãos e de respeito destes para com as autoridades constituídas. ${ }^{73}$ Com uma ideologia construída para frear a parcela do povo ativo na política, federalistas começaram a defender um novo e radical papel para os tribunais. Este partido tornou o argumento de evitar a tirania da maioria o âmago da justificativa para a existência do judicial review, além de uma boa razão para preferir os juízes e não os legisladores como intérpretes finais da Constituição. ${ }^{74}$

Com efeito, o medo das maiorias tirânicas era ubíquo entre os federalistas, que adotaram como cânone o argumento surgido em meados de 1800 de que as cortes eram especialmente responsáveis pela interpretação constitucional e que sua palavra deveria ser final ${ }^{75}$ - teoria que é reconhecida atualmente como supremacia judicial. As palavras de James Kent, professor e dedicado federalista, em sua obra, enfatizam bem esse sentimento do partido com relação as cortes e ao povo ao afirmar que os juízes "são os adequados e pretendidos guardiões dos limites da Constituição" protegendo "os direitos da minoria" das "paixões e da vingança da maioria".76

Esta ideia de supremacia judicial advogada pelos federalistas não foi desde logo acolhida, ao contrário, foi decisivamente repudiada por um longo período após seu surgimento. Nos anos que se seguiram a decisão de Marbury, houve um longo período de domínio político republicano, contribuindo para que o partido Federalista se dissolvesse. Com isso, os princípios republicanos e o entendimento republicano de constitucionalismo tornaram-se prevalecentes entres os norte-americanos. Quanto à ideia de supremacia judicial, esta ficou hibernada, sem contudo desaparecer, ressurgindo apenas algumas décadas depois. ${ }^{77}$

A partir desse contorno, observa-se que a decisão de Marshall em Marbury é melhor compreendida ao considera-la também um assunto político e não meramente jurídico ${ }^{78}$, tendo sido proferida quando os ideais do constitucionalismo popular

\footnotetext{
${ }^{73}$ KRAMER, Larry. "The Interest of the Man": James Madison, Popular Constitutionalism, and the Theory of Deliberative Democracy. Valparaiso University Law Review, vol. 41, n. 2, p. 697-754, winter, 2006.

${ }^{74}$ KRAMER, Larry. The People Themselves: Popular Constitutionalism and Judicial Review, New York: Oxford University Press, 2004. p. 111, 129-132.

${ }^{75}$ KRAMER, Larry. The People Themselves: Popular Constitutionalism and Judicial Review, New York: Oxford University Press, 2004. p. 135, 139.

${ }^{76}$ KENT, James. An Introductory Lecture To A Course Of Law Lectures, New York: Printed by Francis Childs, 1794. Disponível Em: <https://books.google.com.br/books?isbn=1886363919>.

${ }_{77}$ KRAMER, Larry. The People Themselves: Popular Constitutionalism and Judicial Review, New York: Oxford University Press, 2004. p. 140-144.

${ }^{78}$ Vide: "To understand Marbury fully, we must appreciate it not simply as a case deciding a legal dispute between William Marbury and James Madison, but as a political act contributing to the establishment of a
} 
vigoravam e eram dominantes. Neste contexto, a ideia de supremacia judicial era marginal, defendida por uma minoria de pessoas, e dada a fragilidade do departamento judiciário, dificilmente este teria se arrogado o intérprete final do sentido constitucional.

É no decorrer da história, portanto, que a doutrina da supremacia judicial passou a ganhar mais visibilidade. E não se pode afirmar outra coisa senão que Marshall, em razão de uma circunstância politicamente delicada em Marbury, somada a impotência da Corte, evitou os argumentos federalistas e ambiciosos em relação ao judicial review para simplesmente afirmar que as cortes tinham o mesmo dever e a mesma obrigação de aplicar a Constituição que outros departamentos do governo.

\section{CONSIDERAÇÕES FINAIS}

Por muito tempo se pensou que o problema do uso retórico de Marbury estaria na reformulação deste precedente em uma forma mítica, mais especificamente para elevá-lo como caso que criou ou estabeleceu o judicial review. Há pouco tempo, teses revisionistas chamaram atenção para outra dimensão da utilidade do mito sobre o precedente, que é a dimensão abraçada pela Suprema Corte e seus acadêmicos defensores, que escondem as fundações da supremacia judicial fazendo parecer que esta doutrina sempre foi dominante na teoria constitucional norte-americana. Em resposta as afirmações agressivas do poder judicial, este, entre tantos outros, aspectos das histórias contadas para justificar a supremacia judicial são expostos pelo movimento crítico denominado constitucionalismo popular.

Como visto, a defesa da supremacia judicial segundo um raciocínio inspirado na decisão Marbury v. Madison somente torna-se possível em uma interpretação descontextualizada. Este tipo de interpretação do caso não segue sem objeções. Por desconsiderar o papel dos demais intérpretes constitucionais no contexto temporal da decisão é alvo de críticas.

As teses críticas de Larry Kramer e Keith Whittington buscam fazer repensar certos argumentos que são quase ritualisticamente proferidos para justificar a primazia do judiciário na interpretação constitucional ao identificar o erro em apontar Marbury como pedra de fundação da prática contemporânea do judicial review associada à doutrina da supremacia judicial. Assim, a leitura proposta por estes autores pode ser entendida como um clamor por uma coerente teoria que justifique a ampliação do alcance da autoridade judicial, que segundo eles, ainda não foi apresentada.

discourse of constitutionalism in which the realms of law and politics merge". (O'FALLON, James. Marbury, Stanford Law Review, vol. 44, n. 2, jan. p. 219-260, 1992. p. 221.) 


\section{REFERÊNCIAS}

ALSTYNE, William Van. A Critical Guide to Marbury v. Madison. Duke Law Journal, vol. 18, p. 1-47, 1969.

BICKEL. Alexander. The Least Dangerous Branch: The Supreme Court At The Bar Of Politics. New Haven: Yale University Press, 1962.

CHEMERINSKY, Erwin. Federal Jurisdiction. New York: Aspen Publishers, 2007.

CLINTON, Robert Lowry. Marbury V. Madison and Judicial Review. Lawrence: University of Kansas Press, 1989.

DOUGLAS, Davison. The Rhetorical Use Of Marbury V. Madison: The Emergence Of a "Great Case". Wake Forest Law Review, vol. 38, p. 375-413, 2003.

DWORKIN, Ronald. Freedom's Law: The Moral Reading of the American Constitution. Cambridge: Harvard University Press, 1996.

FRIEDMAN, Barry. The Myths of Marbury. In: TUSHNET, Mark. (Ed.). Arguing Marbury v. Madison. California: Stanford University Press, 2005.

FRIEDMAN. Barry. The Will Of The People: How Public Opinion Has Influenced The Supreme Court And Shaped The Meaning Of The Constitution. New York: Farrar, Straus and Giroux, 2009.

GRABER, Mark. Establishing judicial review: Marbury and the judicial act of 1789. Tulsa Law Review, v. 38, n. 4, p. 609-650, 2003.

GRIFFIN, Stephen. The Age of Marbury: Judicial Review in a Democracy of Rights. In: TUSHNET, Mark. (Ed.). Arguing Marbury v. Madison. California: Stanford University Press, 2005

KENT, James. An Introductory Lecture To A Course Of Law Lectures, New York: Printed by Francis Childs, 1794. Disponível Em: <https://books.google.com.br/books?isbn=1886363919>. Acesso em 09 de mai. 2017.

KLARMAN, Michael. How Great were the 'Great' Marshall Court Decisions?. Virginia Law Review, vol. 87, p. 1111-1154, oct., 2001.

KRAMER, Larry. "The Interest of the Man": James Madison, Popular Constitutionalism, and the Theory of Deliberative Democracy. Valparaiso University Law Review, vol. 41, n. 2, p. 697-754, winter, 2006.

KRAMER, Larry. Generating Constitutional Meaning. California Law Review, vol. 94, n. 5, p. 14391453, oct. 2006.

KRAMER, Larry. Marbury And The Reatreat From Judicial Supremacy. Constitutional Commentary, Vol. 20, n. 2, p. 205-230, summer, 2003. 
KRAMER, Larry. Popular Constitutionalism, Circa 2004. California Law Review, vol. 92, n. 4, p. 959 1011, jul. 2004.

KRAMER, Larry. The Pace and Cause of Change. Marshall Law Review, vol. 37, n. 2, p. 357-389, winter, 2004.

KRAMER, Larry. The People Themselves: Popular Constitutionalism and Judicial Review. New York: Oxford University Press, 2004.

KRAMER, Larry. The Supreme Court 2000 Term: Foreword: We the Court. Harvard Law Review, vol. 115, p. 4-169, jan., 2001.

MCREE, Griffith John. Life and Correspondence of James Iredell: One of the Associate Justices of the Supreme Court of the United States, D. Appleton, 1857. Disponível em: <https://books. google.com.br/books?id=e1F7AAAAMAAJ>. Acesso em 09 mai. 2017.

O'FALLON, James. Marbury. Stanford Law Review, vol. 44, n. 2, jan. p. 219-260, 1992.

RAKOVE, Jack. The Origins of Judicial Review: A Plea for New Contexts. Stanford Law Review, vol. 49, p. 1060-64, 1997.

RUGER, Theodore. "A Question Which Convulses A Nation": The Early Republic's Greatest Debate About Judicial Review Power. Harvard Law Review, vol. 117, p. 826-890, 2004.

SNOWISS, Sylvia. Judicial Review and the Law of the Constitution. New Haven: Yale University Press. 1990

The Federalist Papers, n. 78, 1788. Disponível em: <https://www.congress.gov/resources/display/ content/The+Federalist+Papers $>$. Acesso em 09 mai. 2017.

TREANOR, William Michael. Judicial Review Before Marbury. Stanford Law Review, vol. 58, p. 455$462,2005$.

WHITTINGTON, Keith. Extrajudicial Constitutional Interpretation: Three Objections and Responses. North Carolina Law Review, vol. 80, n. 3, p. 773-852, 2002.

WHITTINGTON, Keith. Political Foundations of Judicial Supremacy. Princeton: Princeton University Press, 2007.

WHITTINGTON, Keith; RINDERLE, Amanda. Making A Mountain Out Of A Molehill? Marbury And The Construction Of The Constitutional Canon. Hastings Constitutional Law Quarterly, Forthcoming, fev. 2012. Disponível em: <https://ssrn.com/abstract=2003083>. Acesso em 09 mai 2017. WOLFE, Christopher. The Rise Of Modern Judicial Review: From Constitutional Interpretation To Judge-Made Law, New York: Basic, 1986.

WOOD, Gordon. The Origins Of Judicial Review Revisited, Or How The Marshall Court Made More Out Of Less. Washington \& Lee Law Review, vol. 56, n. 3, p. 787-803, 1999. 